\title{
Non-vaccine-Preventable Infections
}

\subsection{Destination}

Certain infections are restricted to specific geographical locations, so knowledge regarding regions in which particular diseases can be acquired is important when advising travellers. Appendix A, common travel destinations, lists the important infectious hazards of the common destinations.

\subsection{Types of Activities}

Infections may be transmitted sexually, parenterally, by ingestion, by inhalation, by a percutaneous route or via an insect vector. Thus, the following activities or behaviours may put the traveller at risk of certain specific infectious agents:

- Eating and drinking

- Exposure to insects

- Recreational, occupational and animal exposures

- Sexual encounters

- Substance abuse

- Contact with blood

- Exposure to infectious aerosols

Relevant infections/infestations according to their mode of exposure and their geographical distributions are outlined in Tables 5.1, 5.2, 5.3, and 5.4. The importance of safe behaviour in these areas is emphasised in Chap. 1 (see Sect. 1.7). After determining which infections the traveller may be at risk of contracting, advise the traveller according to the information under each specific infection outlined in this chapter. 
Table 5.1 Food and drink

\begin{tabular}{|c|c|c|}
\hline Significant exposures & Infections & Main geographic sites \\
\hline \multirow[t]{4}{*}{$\begin{array}{l}\text { Unpasteurised milk } \\
\text { or cheese }\end{array}$} & Brucellosis & $\begin{array}{l}\text { Worldwide, especially Mediterranean } \\
\text { countries, Middle East and Central and } \\
\text { South America }\end{array}$ \\
\hline & Listeriosis & Worldwide \\
\hline & Salmonellosis & Worldwide \\
\hline & Q fever & Worldwide \\
\hline \multirow{6}{*}{$\begin{array}{l}\text { Raw or undercooked } \\
\text { fish or seafood }\end{array}$} & Hepatitis A & Worldwide \\
\hline & Hepatitis E & $\begin{array}{l}\text { Asia, Africa, Middle East, Central } \\
\text { America }\end{array}$ \\
\hline & Vibrio spp. & Worldwide \\
\hline & Paragonimiasis & $\begin{array}{l}\text { Mainly Asia (especially China, India, } \\
\text { Myanmar), also Latin America and } \\
\text { Africa }\end{array}$ \\
\hline & Clonorchiasis & $\begin{array}{l}\text { Asia, especially China, Japan, Taiwan, } \\
\text { Korea, Vietnam, Laos, Cambodia }\end{array}$ \\
\hline & Gnathostomiasis & Southeast Asia, South America \\
\hline \multirow{6}{*}{$\begin{array}{l}\text { Raw or undercooked } \\
\text { meat }\end{array}$} & Salmonellosis & Worldwide \\
\hline & Campylobacter spp. & Worldwide \\
\hline & $\begin{array}{l}\text { Pathogenic E. coli and } \\
\text { other bacterial infections }\end{array}$ & Worldwide \\
\hline & Trichinosis & Widespread, especially Asia and Mexico \\
\hline & Toxoplasmosis & Worldwide \\
\hline & Cysticercosis & Asia, Africa, South America \\
\hline $\begin{array}{l}\text { Watercress, raw } \\
\text { salads }\end{array}$ & Fascioliasis & $\begin{array}{l}\text { South America, Caribbean, Australia, } \\
\text { Asia, Middle East, France }\end{array}$ \\
\hline
\end{tabular}

Table 5.2 Vector-borne infections

\begin{tabular}{|c|c|c|}
\hline Insect vector & Infections & Main geographic sites \\
\hline \multirow[t]{8}{*}{ Mosquitoes } & Malaria & Many tropical areas-see Chap. 3 \\
\hline & Dengue fever & $\begin{array}{l}\text { Tropics of Asia, Africa, Central and South America, } \\
\text { Pacific }\end{array}$ \\
\hline & Chikungunya & $\begin{array}{l}\text { Most of Sub-Saharan Africa, India, Southeast Asia, } \\
\text { Indonesia and Philippines }\end{array}$ \\
\hline & Zika virus & Africa, Southeast Asia, Pacific, Americas \\
\hline & $\begin{array}{l}\text { Viral haemorrhagic } \\
\text { fevers }\end{array}$ & $\begin{array}{l}\text { Different viruses in different countries-mainly } \\
\text { Africa, South America, Southeast Asia }\end{array}$ \\
\hline & Lymphatic filariasis & $\begin{array}{l}\text { Different species in different tropical areas, } \\
\text { especially Pacific Islands, Asia, Africa, South } \\
\text { America }\end{array}$ \\
\hline & Japanese encephalitis & $\begin{array}{l}\text { Southeast Asia, Pakistan, Sri Lanka, Bangladesh, } \\
\text { Papua New Guinea, Torres Strait Islands }\end{array}$ \\
\hline & Yellow fever & Limited to areas in Africa and South America \\
\hline
\end{tabular}


Table 5.2 (continued)

\begin{tabular}{|c|c|c|}
\hline Insect vector & Infections & Main geographic sites \\
\hline \multirow[t]{8}{*}{ Ticks } & $\begin{array}{l}\text { Rickettsial spotted } \\
\text { fevers }\end{array}$ & Worldwide—different species in different areas \\
\hline & Lyme disease & $\begin{array}{l}\text { North America, Europe, Russian Federation, China, } \\
\text { Japan }\end{array}$ \\
\hline & Ehrlichiosis & $\begin{array}{l}\text { Mainly southeastern, South Central, northeastern } \\
\text { and mid-Atlantic regions of the United States }\end{array}$ \\
\hline & Babesiosis & $\begin{array}{l}\text { Northeastern United States (Massachusetts, } \\
\text { New York City, Rhode Island and Connecticut) and } \\
\text { Europe (especially France, Great Britain and } \\
\text { Ireland, Sweden, Spain, Portugal and Germany) }\end{array}$ \\
\hline & Tularaemia & $\begin{array}{l}\text { North America, Central Europe, former Soviet } \\
\text { Union, China, Japan }\end{array}$ \\
\hline & Congo-Crimean fever & Africa, Middle East, Russia, China \\
\hline & $\begin{array}{l}\text { Tick-borne } \\
\text { encephalitis }\end{array}$ & $\begin{array}{l}\text { Central Europe (Austria, Germany), Russian } \\
\text { Federation, United States }\end{array}$ \\
\hline & $\begin{array}{l}\text { Endemic relapsing } \\
\text { fever }\end{array}$ & $\begin{array}{l}\text { Tropical Africa, Spain, Saudi Arabia, India, Central } \\
\text { Asia, North and South America }\end{array}$ \\
\hline Tsetse fly & $\begin{array}{l}\text { African } \\
\text { trypanosomiasis }\end{array}$ & $\begin{array}{l}\text { Tropical Africa, especially Uganda, Angola, } \\
\text { Democratic Republic of Congo, Sudan }\end{array}$ \\
\hline $\begin{array}{l}\text { Triatomine } \\
\text { ('kissing') } \\
\text { bugs }\end{array}$ & $\begin{array}{l}\text { American } \\
\text { trypanosomiasis }\end{array}$ & Mexico, Central and South America \\
\hline \multirow[t]{3}{*}{ Sand flies } & $\begin{array}{l}\text { Bartonella } \\
\text { bacilliformis }\end{array}$ & Mountain valleys of Peru, Ecuador and Colombia \\
\hline & $\begin{array}{l}\text { Leishmaniasis } \\
\text { (cutaneous and } \\
\text { visceral) }\end{array}$ & $\begin{array}{l}\text { Different species in different areas, especially } \\
\text { Central/South America, Middle East, Asia, India, } \\
\text { Mediterranean region, Sub-Saharan Africa }\end{array}$ \\
\hline & Sand fly fever & Mediterranean region \\
\hline \multirow[t]{3}{*}{ Fleas } & Plague & $\begin{array}{l}\text { Western United States, South America, Africa, } \\
\text { Southeastern Europe, Southeast Asia, Russian } \\
\text { Federation }\end{array}$ \\
\hline & $\begin{array}{l}\text { Murine typhus } \\
\text { (Rickettsia typhi) }\end{array}$ & Worldwide \\
\hline & $\begin{array}{l}\text { Cat-scratch } \\
\text { (Bartonella henselae) }\end{array}$ & Worldwide \\
\hline Mites & $\begin{array}{l}\text { Scrub typhus (Orientia } \\
\text { tsutsugamushi) }\end{array}$ & $\begin{array}{l}\text { Mainly tropical Asia, Pacific Islands, northern } \\
\text { Australia }\end{array}$ \\
\hline Black flies & Onchocerciasis & $\begin{array}{l}\text { West and Central Africa, Latin America, Arabian } \\
\text { Peninsula }\end{array}$ \\
\hline \multirow[t]{3}{*}{ Lice } & $\begin{array}{l}\text { Epidemic relapsing } \\
\text { fever }\end{array}$ & $\begin{array}{l}\text { Ethiopia, Sudan, Central Africa, South America, } \\
\text { Asia }\end{array}$ \\
\hline & $\begin{array}{l}\text { Epidemic typhus } \\
\text { (Rickettsia prowazekii) }\end{array}$ & Mexico, Central and South America, Africa, Asia \\
\hline & $\begin{array}{l}\text { Trench fever } \\
\text { (Bartonella quintana) }\end{array}$ & Worldwide \\
\hline $\begin{array}{l}\text { Horse and deer } \\
\text { flies }\end{array}$ & Loiasis & Limited to Western and Central Africa \\
\hline
\end{tabular}


Table 5.3 Recreational, occupational or animal exposures

\begin{tabular}{|c|c|c|}
\hline $\begin{array}{l}\text { Significant } \\
\text { exposures }\end{array}$ & Infections & Main geographic sites \\
\hline \multirow{3}{*}{$\begin{array}{l}\text { Swimming, } \\
\text { rafting, bathing in } \\
\text { freshwater }\end{array}$} & Schistosomiasis & $\begin{array}{l}\text { Africa, Middle East, East Asia, } \\
\text { Philippines, South America, Caribbean }\end{array}$ \\
\hline & Leptospirosis & Worldwide \\
\hline & Free living amoebae & Worldwide \\
\hline \multirow[t]{5}{*}{$\begin{array}{l}\text { Soil exposure or } \\
\text { digging }\end{array}$} & Coccidioidomycosis & $\begin{array}{l}\text { Southern United States, Central America, } \\
\text { Mexico, Venezuela, Colombia, Paraguay, } \\
\text { Argentina }\end{array}$ \\
\hline & Paracoccidioidomycosis & Tropical Americas, especially Brazil \\
\hline & Blastomycosis & $\begin{array}{l}\text { Mainly central/southeastern United } \\
\text { States, Canada, DRC, Tanzania, South } \\
\text { Africa }\end{array}$ \\
\hline & $\begin{array}{l}\text { Talaromyces } \\
\text { (formerly Penicilliosis) }\end{array}$ & Southeast Asia \\
\hline & Melioidosis & $\begin{array}{l}\text { Widespread, but mainly Southeast Asia } \\
\text { (especially Thailand), tropical Australia }\end{array}$ \\
\hline Cave exploration & Histoplasmosis & $\begin{array}{l}\text { Worldwide, particularly in North and } \\
\text { South America, East Asia, Africa }\end{array}$ \\
\hline \multirow{2}{*}{$\begin{array}{l}\text { Walking barefoot } \\
\text { or lying on soil/ } \\
\text { sand }\end{array}$} & Strongyloidiasis & Mainly humid tropical areas \\
\hline & Cutaneous larva migrans & Tropical areas \\
\hline \multirow[t]{8}{*}{$\begin{array}{l}\text { Contact with } \\
\text { animals or animal } \\
\text { products }\end{array}$} & Brucellosis & $\begin{array}{l}\text { Worldwide, especially the Middle East, } \\
\text { Mediterranean countries and Central/ } \\
\text { South America }\end{array}$ \\
\hline & Q fever & Worldwide \\
\hline & Anthrax & $\begin{array}{l}\text { Worldwide, especially South/Central } \\
\text { America, Asia, Africa, southern and } \\
\text { eastern Europe }\end{array}$ \\
\hline & Tularaemia & $\begin{array}{l}\text { North America, Central Europe, former } \\
\text { Soviet Union, China, Japan }\end{array}$ \\
\hline & Plague & $\begin{array}{l}\text { Western United States, South America, } \\
\text { Africa, southeastern Europe, Southeast } \\
\text { Asia, Russian Federation }\end{array}$ \\
\hline & Rabies & $\begin{array}{l}\text { Worldwide except countries listed in } \\
\text { Table } 2.11\end{array}$ \\
\hline & Toxoplasmosis & Worldwide \\
\hline & MERS & Arabian Peninsula \\
\hline \multirow[t]{5}{*}{ Rodents } & Hantavirus & $\begin{array}{l}\text { China, South Korea, United States } \\
\text { (especially Four Corners area), South } \\
\text { America }\end{array}$ \\
\hline & Plague & $\begin{array}{l}\text { Western United States, South America, } \\
\text { Africa, southeastern Europe, Southeast } \\
\text { Asia, Russian Federation }\end{array}$ \\
\hline & $\begin{array}{l}\text { Murine typhus (Rickettsia } \\
\text { typhi) }\end{array}$ & Worldwide \\
\hline & Viral haemorrhagic fevers & $\begin{array}{l}\text { Different species in different countries, } \\
\text { e.g. Lassa fever in West Africa }\end{array}$ \\
\hline & Lassa fever & $\begin{array}{l}\text { West Africa, especially Sierra Leone, } \\
\text { Guinea, Liberia, Nigeria }\end{array}$ \\
\hline
\end{tabular}


Table 5.4 Sexual or parenteral exposures

\begin{tabular}{l|l|l}
\hline Significant exposures & Infections & $\begin{array}{l}\text { Main geographic } \\
\text { sites }\end{array}$ \\
\hline Sexual contacts & $\begin{array}{l}\text { HIV, hepatitis B and C, syphilis, } \\
\text { gonorrhoea, chlamydia, etc. }\end{array}$ & Worldwide \\
\hline $\begin{array}{l}\text { Transfusions, injections, body } \\
\text { piercing, tattoos }\end{array}$ & HIV, hepatitis B, hepatitis C & Worldwide \\
\hline
\end{tabular}

\subsubsection{Infections Acquired Via Ingestion}

The most common health problem acquired via ingestion is travellers' diarrhoea. This topic is addressed in detail in Chap. 4, which also describes general food and water hygiene measures that should be followed by all travellers, particularly those going to developing countries. Table 5.1 sets out the important infections that can be acquired by ingestion of specific foods.

\subsubsection{Vector-Borne Diseases}

Many infections (see Table 5.2) are transmitted by the bite of an insect, and vectorborne infections are among the most common cause of fever in returned travellers. Mosquitoes are the main insect vector of disease, but there are many other insect vectors, including ticks, flies, fleas, sand flies, lice and triatomine bugs, that may be responsible. The same preventive measures are generally effective against all of them:

- Covering up with long sleeves and long pants

- Applying repellent (containing DEET or picaridin) on bare skin

- Sleeping in screened accommodation or under a mosquito net (preferably permethrin-impregnated)

- Impregnating clothing and bed sheets with permethrin

\subsubsection{Diseases Transmitted Via Recreational and Occupational Activities}

A number of recreational and occupational activities (see Table 5.3) can put travellers at risk of infections, many of which are transmitted by the percutaneous route. To minimise exposure to these infections:

- Avoid walking barefoot, especially in areas with potentially contaminated soil; shoes, sandals or sneakers should be worn.

- Avoid swimming in beaches that might be contaminated with human sewage or with dog faeces, as this can be a source of many infections.

- Avoid swimming, wading or canoeing in freshwater that may be a source of infections including schistosomiasis and leptospirosis. 
- Avoid direct skin contact with sand as this may lead to exposure to cutaneous larva migrans. Travellers should be advised to wear clothes or to lie on a towel or blanket.

Exposure to soil, excavations and caves may also be a source of infections such as endemic fungi. Thus, whenever possible, tourists should avoid dust exposure in contaminated areas.

Many infections including rabies, anthrax and others are transmitted by animals. Travellers should avoid animal bites or scratches by abstaining from feeding, patting, playing or interacting with animals.

\subsubsection{Diseases Transmitted Via Sexual or Parenteral Exposure}

People are at risk of sexually and/or parenterally transmitted infections (see Table 5.4) both at home and during travel but may be more likely to engage in unsafe behaviour while travelling. Therefore the importance of safe behaviour during travel needs to be emphasised.

\subsection{Specific Infections}

\subsubsection{African Trypanosomiasis ('Sleeping Sickness')}

\section{Organism}

Trypanosoma brucei gambiense (West African trypanosomiasis) or Trypanosoma brucei rhodesiense (East African trypanosomiasis).

\section{Geographical Distribution}

- Tropical Africa between latitudes $15^{\circ} \mathrm{N}$ and $20^{\circ} \mathrm{S}$, especially remote and rural regions where tsetse flies are prevalent

- Epidemic disease in certain provinces in Angola, Democratic Republic of Congo, Sudan and Uganda

- Moderate-low prevalence in Benin, Burkina Faso, Cameroon, Central African Republic, Chad, Congo, Côte d'Ivoire, Guinea, Gabon, Ghana, Kenya, Mali, Mozambique, Nigeria, Tanzania, Togo and Zambia

\section{Transmission and Risks to Travellers}

Transmitted via the bite of an infected tsetse fly. This rare infection in travellers is usually due to East African trypanosomiasis (due to T. brucei rhodesiense), which occurs in eastern and southern Africa.

Travellers to urban areas are not at risk. Humans are exposed to bites while hunting or on wildlife safari in game park areas, especially near Lake Victoria or in parks in Sub-Saharan Africa (including Serengeti, Ngoro Ngoro, Amboseli and Akagera). A cluster of East African disease has occurred from Tanzania. 


\section{IIIness}

Travellers with East African disease often have a very short incubation period (few days) and present acutely with fever, a transient morbilliform rash, and meningoencephalitis, with progressive neurologic involvement over 1-4 weeks. Ultimately coma and death ensue. West African trypanosomiasis causes a more chronic infection, which may not result in neurological involvement for several years.

\section{Prevention}

Tsetse flies are active during the day and are attracted to large moving objects and dark blue colours.

- Wear long-sleeved shirts and long pants in endemic areas.

- Avoid bright-coloured clothing.

- Keep car windows closed and don't ride in open vehicles.

- Permethrin and DEET have some value but are not always effective.

- There is no vaccine or preventive drug available.

\subsubsection{American Trypanosomiasis (Chagas' Disease)}

\section{Organism}

Trypanosoma cruzi.

\section{Geographical Distribution}

- Found only in South and Central America

- Endemic areas in Argentina, Brazil, Bolivia, Belize, Chile, Colombia, Costa Rica, Ecuador, El Salvador, French Guiana, Guyana, Guatemala, Honduras, Mexico, Nicaragua, Uruguay, Paraguay, Peru, Panama and Venezuela

\section{Transmission and Risks to Travellers}

Transmitted by the triatomine bug ('kissing bug'), a small insect that lives in crevices of dirt walls and roofs of rural dwellings. It usually feeds at night. Travellers sleeping in local adobe huts in rural areas or areas off the normal tourist track may be at risk. Visitors to large cities or remote jungle ruins are not at risk. Oral transmission can also occur via ingestion of foods contaminated with triatomines or their faeces.

\section{Illness}

Early infections are usually asymptomatic. The long-term complications of infection include cardiomyopathy and paralysis of the intestines and oesophagus ('megaoesophagus' and 'megacolon').

\section{Prevention}

- It is best to avoid living in or camping near adobe huts. If it is not possible to avoid sleeping in a hut, sleep in the centre of the room away from the walls. 
- Nocturnal application of insect repellents and sleeping under a mosquito net will also help prevent bites.

- Travellers staying in hotels or resorts are not at significant risk for contracting the disease.

- Blood transfusions should be avoided in endemic areas.

- There is currently no vaccine or preventive drug for Chagas' disease.

\subsubsection{Amoebiasis}

\section{Organism}

The protozoon Entamoeba histolytica.

\section{Geographical Distribution}

E. histolytica has a worldwide distribution. It is endemic in Africa, Mexico and Central and South America.

\section{Transmission and Risks to Travellers}

It is transmitted by ingestion of contaminated water.

\section{Illness}

Several forms of the disease are recognised:

1. A noninvasive disease producing luminal intestinal disease (causing abdominal bloating, cramps and diarrhoea) is most frequent.

2. Amoebic colitis produces severe, bloody diarrhoea. Toxic megacolon with gastrointestinal haemorrhage, perforation and death may occur.

3. Extraintestinal infection. This most commonly manifests as liver abscesses.

\section{Prevention}

Avoid uncooked food and contaminated water (see Chap. 4).

\subsubsection{Brucellosis}

\section{Organism}

There are different species, but the major travel- and food-related infections are caused by Brucella melitensis and Brucella abortus.

\section{Geographical Distribution}

Endemic in Mediterranean countries (especially Greece, Spain, Italy and Portugal), the Middle East (especially Iraq, Iran, Egypt and Kuwait), India and Latin America (especially Peru, Argentina and Mexico). 


\section{Transmission and Risks to Travellers}

Different species are transmitted in different ways, including inhalation of infected aerosols, direct contact with infected animals and ingestion of unpastuerised dairy products. $B$. melitensis is particularly associated with ingestion of contaminated goats' milk or cheese.

\section{Illness}

Acute infection is associated with fever, myalgia, arthralgia and organomegaly. Relapsing forms and chronic infection can lead to complications such as arthritis, spondylitis, orchitis, uveitis and depression.

\section{Prevention}

- Avoid contact with livestock.

- Avoid ingestion of unpasteurised dairy products.

\subsubsection{Buruli Ulcer}

\section{Organism}

Buruli ulcer is caused by Mycobacterium ulcerans.

\section{Geographical Distribution}

This disease is found mainly in West and Central Africa, but also commonly in the coastal regions of southeastern Victoria and far North Queensland in Australia. Disease cases are also reported from South America, Asia and the Pacific. The disease is found in focal areas, usually associated with wetlands or rivers.

\section{Transmission and Risks to Travellers}

The exact transmission route to humans is unknown, but it may be via skin contact with contaminated soils or water, or the bite of a vector like a mosquito or sand fly. Travellers are occasionally infected on visiting endemic areas, even for only a few hours.

\section{Illness}

As the average incubation period is estimated to be between 4 and 5 months, many travellers develop symptomatic disease on return home. The classic lesion is a painless ulcer, usually on the limbs, which slowly progresses. However non-ulcerative forms can occur that include papules, nodules, plaques and aggressive oedematous lesions that resemble cellulitis. Diagnosis is best made by a PCR of lesion fluid or tissue, although biopsy specimens can be examined for acid-fast bacilli and sent for mycobacterial cultures.

\section{Prevention}

As the route of transmission is unknown, prevention measures are not defined. However potential ways to minimise infection include: 
- Wearing protective clothing to arms and legs when exposed to the environment in endemic areas

- Minimising insect bites through use of repellents

- Covering cuts and injuries to avoid contact with soil or water

\subsubsection{Chikungunya Virus}

\section{Organism}

Caused by the Chikungunya virus, which is an alphavirus.

\section{Geographical Distribution}

Chikungunya virus has long been known to be endemic in tropical Africa and Asia. The virus is present throughout much of Africa, with transmission thought to occur mainly between mosquitoes and monkeys. After a long period of absence, outbreaks of Chikungunya appeared in Indonesia in 1999, and in 2006 reappeared in India and various Indian Ocean islands, including Comoros, Mauritius, Reunion and Seychelles (see Map 5.1). In 2013-2014, there was a huge outbreak in the Americas, with over a million cases. Ongoing cases are continuing to occur in many parts of the world, although at a lower frequency. Among populations with no prior immunity, Chikungunya outbreaks can be explosive, with attack rates as high as $70 \%$. Chikungunya fever displays interesting epidemiological profiles, as major epidemics appear and disappear cyclically, with variable interepidemic periods.

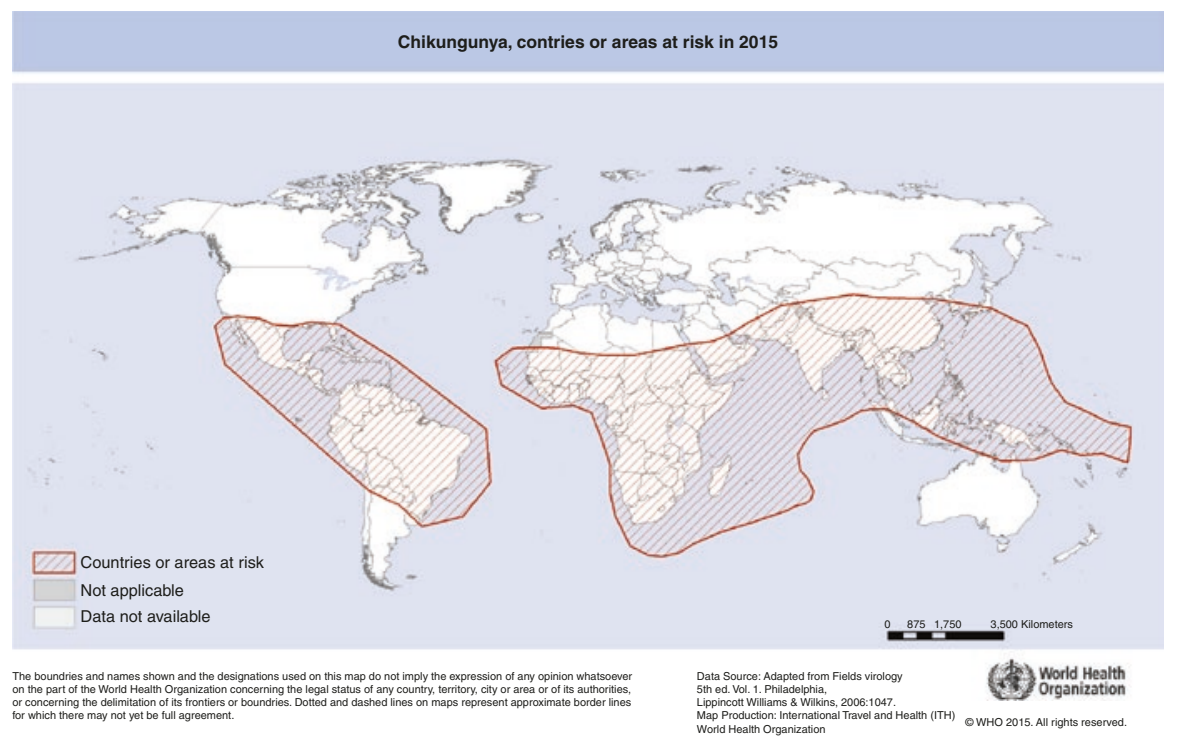

Map 5.1 Global distribution of Chikungunya. Source: http://gamapserver.who.int/mapLibrary/ Files/Maps/Global_Chikungunya_ITHRiskMap.png?ua=1 


\section{Transmission and Risks to Travellers}

Transmitted by Aedes mosquitoes (Aedes aegypti and Aedes albopictus) which bite during the daytime. Popular travel destinations have been affected by recent outbreaks. As a result, many travellers have developed Chikungunya, including a number of cases diagnosed in travellers returning to Australia. Local European transmission of Chikungunya virus has occurred in northeastern Italy and in France from returned viremic travellers.

\section{IIIness}

The name Chikungunya is derived from an African word meaning 'that which bends up'. The clinical manifestations of this illness range from a syndrome not unlike Ross River virus to a more severe presentation resembling dengue fever (see below). Common symptoms include fever, polyarthralgia/arthritis, gastrointestinal symptoms, maculopapular skin rash and conjunctivitis. It is usually a self-limiting illness that has an incubation period of 2-4 days. Rarely serious complications, such as neuroinvasive disease and chronic inflammatory arthritis, can occur. There are no specific treatments for Chikungunya virus infection.

\section{Prevention}

The only way to prevent infection is to avoid mosquito bites as there is no vaccine currently available. Recovery from infection provides lifelong immunity. All travellers to endemic areas should use personal insect protective measures such as:

- Remaining in well-screened or completely enclosed air-conditioned areas.

- Using insect repellent on exposed skin.

- Wearing clothing that reduces the amount of exposed skin.

- Using aerosol insecticides indoors.

- Eliminating any standing water in and around the dwelling where Aedes aegypti may breed, such as uncovered water containers, pot plant bases, roof gutters, drains, containers, tyres or depressions in the ground (see also Chap. 3).

\subsubsection{Ciguatera}

\section{Toxin-Mediated Disease}

Ciguatera is a form of seafood poisoning caused by eating subtropical or tropical marine fish (e.g. barracuda, red snapper and grouper) that accumulate naturally occurring toxins through their diet.

\section{Geographical Distribution}

Found in warm-water fish near coral reefs between $35^{\circ} \mathrm{N}$ and $35^{\circ} \mathrm{S}$ latitude, it is particularly common in the Pacific Islands and the Caribbean. In Australia, it occurs throughout North Queensland as far south as Bowen, in southern Queensland around Hervey Bay, around the eastern tip of Arnhem Land and around Groote Eylandt in the Gulf of Carpentaria. 


\section{Transmission and Risks to Travellers}

Humans may contact the toxin by eating herbivorous fish or by consuming carnivorous fish that, in turn, have eaten herbivorous fish. The likelihood of ciguatoxin being present and the concentration of ciguatoxins increases with larger carnivorous fish. Not all fish of a given species or from a given locality will be toxic. Areas may become toxic or lose toxicity over time. Freshwater fish are free from ciguatera. As warm-water fish are commonly eaten outside the tropics, the disease can be seen outside endemic areas.

\section{IIIness}

Initial signs of poisoning usually occur within $6 \mathrm{~h}$ and almost always within $24 \mathrm{~h}$ after consumption of toxic fish and include numbness and tingling of the lips, tongue and throat, which may spread to the extremities, a peculiar metallic taste, dry mouth or hypersalivation. Other symptoms include dizziness, malaise, muscle and joint pain and rash.

- In many cases, especially with mild poisoning, the earliest symptoms are gastrointestinal (i.e. sudden abdominal cramps, nausea, vomiting and watery diarrhoea).

- Neurological symptoms include intensified distal paraesthesias, headache, blurred vision, vertigo and muscular weakness to the point of prostration. Altered perception of hot and cold and acute dysaesthesia to cold are distinctive symptoms. Distal sensory loss and loss of deep tendon reflexes are typical findings.

- Cardiovascular manifestations include arrhythmias, bradycardia or tachycardia (typically), atrioventricular block, hypotension and myocardial depression.

The illness is usually self-limiting, and symptoms often subside within several days of onset. Gastrointestinal and cardiovascular features rarely last beyond 24-48 h, although there is a low incidence of death resulting from respiratory and cardiovascular failure. Neurological symptoms, particularly dysaesthesia and weakness, commonly persist for many days or weeks (occasionally months), as do general symptoms of malaise, lassitude and disturbed sleep. Mannitol infusion $(1 \mathrm{~g} / \mathrm{kg}$ intravenously over 30-60 $\mathrm{min}$ ) can dramatically cure ciguatera symptoms, especially if given early for more serious cases. Recovered patients commonly experience relapse of symptoms months to years after recovery, particularly following consumption of alcohol or fish (even fish that is not demonstrably toxic).

\section{Prevention}

- Avoid eating warm-water fish from near shore, especially coral reef fish.

- Avoid eating large coral reef fish $(>2.5 \mathrm{~kg})$, including sharks.

- Do not eat internal organs of fish as toxins tend to collect in these.

- Check with knowledgeable locals about toxic fish and toxic seasons.

- Eat a small piece of a fish at the first sitting. Wash fish flesh prior to consuming (this may reduce the amount of toxin in the flesh of herbivorous fish). 


\subsubsection{Cutaneous Larva Migrans (CLM)}

\section{Organism}

Larval stages of animal hookworms (usually the dog or cat hookworm).

\section{Geographical Distribution}

Occurs worldwide but found mainly in warm, humid climates. Common on coasts of Africa, Southeast Asia, India, Malaysia, Sri Lanka and Thailand.

\section{Transmission and Risks to Travellers}

Larvae directly invade skin. Seen most commonly in children or sunbathers walking barefoot or sitting or lying on damp contaminated ground.

\section{Illness}

CLM is one of the most common dermatologic problems in travellers to tropical countries. It typically causes a very itchy serpiginous track, usually on the foot or lower extremity.

\section{Prevention}

- Wear shoes or sandals and avoid skin contact with soil in endemic areas.

- Prevent children from running around barefoot on the beach.

- Use a beach mat or towel when sunbathing.

\subsubsection{Cysticercosis}

\section{Organism}

Taenia solium (pig tapeworm).

\section{Geographical Distribution}

Occurs predominantly in sub-Saharan Africa, South and Central America, Asia and India.

\section{Transmission and Risks to Travellers}

Humans can be infected with the tapeworm if they ingest cysts from undercooked pork. They may also ingest eggs either via autoinoculation or via contact with someone infected with the tapeworm and develop cysts as intermediate hosts. The cysts most commonly occur in muscles or brain (neurocysticercosis).

\section{Illness}

Most people ( 80\%) with neurocysticercosis remain asymptomatic. Neurocysticercosis however is the most common cause of seizures in endemic areas. Infection can also cause meningitis, subarachnoid haemorrhage, spinal cord lesions, psychiatric problems and hydrocephalus. Outside the central nervous system cysts are usually asymptomatic. 


\section{Prevention}

Freezing or adequately cooking pig meat is important to destroy the cysts.

Attention to handwashing prior to eating and good personal hygiene and handwashing prior to food preparation can prevent infection with eggs.

Treatment for human tapeworm carriers, especially in family contacts.

Infection in pigs can be reduced by preventing their access to human faecal waste.

\subsubsection{Dengue Fever}

\section{Organism}

Caused by a flavivirus with four serotypes (DEN 1, DEN 2, DEN 3 and DEN 4).

\section{Geographical Distribution}

Occurs in tropical and subtropical countries of Asia and Africa, and also in the Caribbean and Central and South America (Map 5.2). The risk to travellers is greatest in the Indian subcontinent, Southeast Asia, Southern China, Central and South America, the Caribbean, Mexico and Africa. There is a lower risk for travellers to Taiwan and the Pacific Islands, and even lower for the Middle East. However, in 2018 Fiji and the Solomon Islands reported large outbreaks of dengue fever. Importation resulting in local transmission occurs periodically in North Queensland.

Distribution of dengue, worldwide, 2016

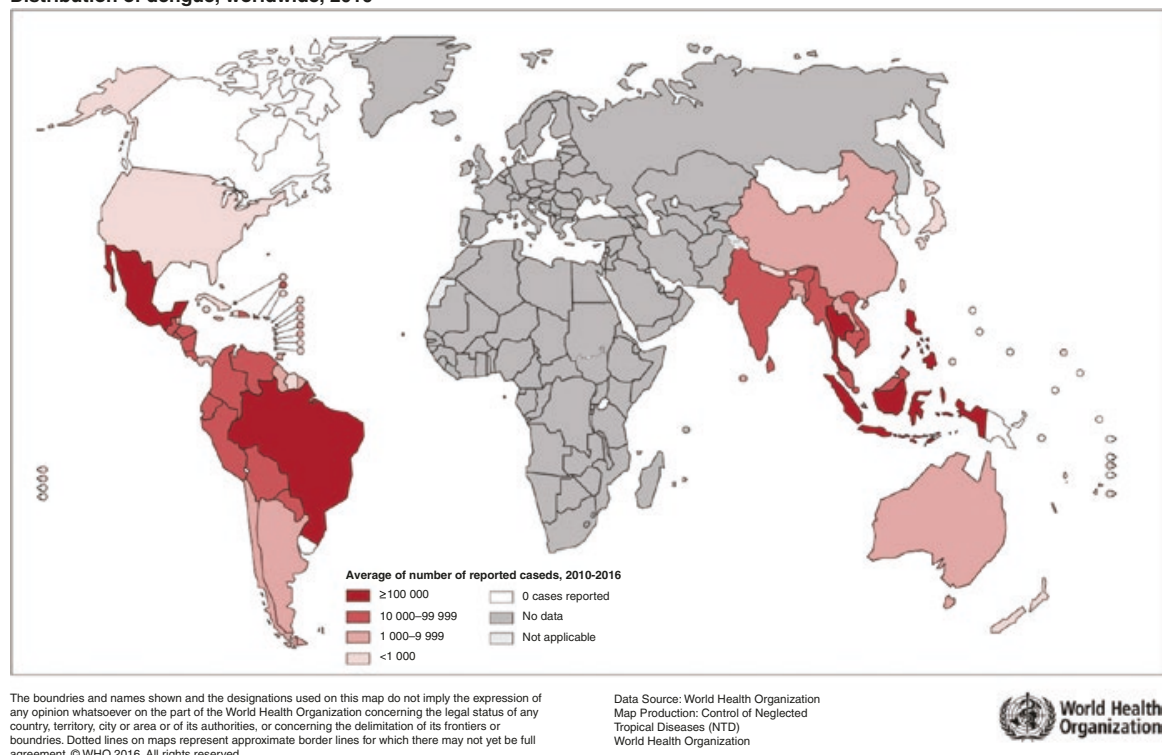

Map 5.2 Global distribution of dengue. Source: https://www.who.int/denguecontrol/epidemiology/ Average_number_suspected_confirmed_dengue_cases_reported_2010_2016_1450px.jpg?ua=1 


\section{Transmission and Risks to Travellers}

Dengue is transmitted by the bite of the Aedes mosquito (Aedes aegypti and Aedes albopictus). These mosquitoes tend to live in and around human habitation, breeding wherever freshwater collects. Thus dengue is predominant in urban centres but may also be found in rural areas. It is rarely found at elevations $>1300 \mathrm{~m}$ (4000 ft.). Aedes mosquitoes are most active in the early morning and late afternoon, but they may feed at any time during the day, especially indoors, in shady areas or during overcast periods.

A marked increase in cases has been observed over the past decade in most countries of the tropics and explosive outbreaks occur. Epidemic transmission is usually seasonal, during and shortly after the rainy season. More severe forms of the disease are very rare among travellers. The risk of complications following infection for travellers who have had past dengue and go back to an endemic area during an outbreak is in the region of $0.5-1.0 \%$. Adults are likely to be at the lower end of this range.

\section{Illness}

Dengue is often asymptomatic. The clinical syndrome follows a short incubation period of 4-7 days followed by an acute biphasic illness characterised by fever, headache, retro-orbital pain, severe aching of muscles and bones and rash. It should be suspected in patients presenting with these symptoms, particularly if they also have thrombocytopenia. If the patient develops fever more than 2 weeks after the last potential time of exposure, dengue is highly unlikely. After 3-4 days, the fever resolves and a fine macular, sometimes scarlatiniform, rash appears. As the rash fades, petechiae appear on the trunk and limbs. In some patients, a second febrile episode occurs (saddleback fever) followed by recovery. A prolonged period of fatigue and listlessness may ensue in the recovery phase. Complete recovery can take 2-4 weeks.

Hepatitis commonly complicates dengue fever, and in approximately $10 \%$ of cases, the serum transaminases may be raised 10 times above the upper limit of normal. Rarely, fulminant hepatitis and death may occur. Dengue may also rarely be complicated by encephalitis.

While the disease is often mild and self-limiting, it may also present in a severe form associated with haemorrhagic complications, shock and, in some cases, death. When complications arise, they most frequently occur 3-7 days after the onset of symptoms. Warning signs for complications include abdominal pain developing after the third day of illness and a falling platelet count. Severe disease is most common in persons $<15$ years of age and in those having their second dengue infection. Second dengue infections predispose to severe infection because cross-protective immunity among the four dengue serotypes is limited. The poorly cross-neutralising antibody resulting from a previous infection results in increased uptake of dengue virus into antigen-presenting cells with an associated increase in viral replication and enhanced pathogenesis. This phenomenon is commonly referred to as antibodydependent enhancement of dengue infection. The relative risk for developing severe dengue in secondary compared with primary infection may be as high as 25-fold. 
However, it is unusual to develop complications after a third episode of dengue infection. The case-fatality rate of severe dengue in most countries is about $5 \%$. Mortality in both severe forms is dramatically reduced by good supportive medical care.

Dengue fever can cause an acute febrile illness in pregnant women and sepsislike illness in neonates. However, no differences in rates of preterm birth, postpartum haemorrhage, low birth weight or neonatal outcomes have been observed, and there are no long-term sequelae.

A number of other infections may present like dengue fever. The differential diagnosis of dengue includes typhoid fever, malaria, leptospirosis, yellow fever, chikungunya and Zika virus infections and meningococcal infection.

\section{Prevention}

The first dengue vaccine, CYD-TDV (Dengvaxia), has now been licensed in 20 countries. The findings from 2 large Phase 3 trials involving over 30,000 participants aged 2-16 years showed that the vaccine efficacy against virologically confirmed dengue, over a 25-month period, in the 9-16-year age group was $65.6 \%$. In this group, vaccination reduced severe dengue by $93 \%$ and dengue hospitalisations by $82 \%$. The vaccine had the greatest efficacy in participants aged more than 9 years and who were seropositive at baseline (76\%) compared to those who were seronegative $(38.8 \%)$. However, there was an increased risk of hospitalised dengue and severe dengue in the seronegative individuals from year 3 onwards during the 66-month observation period, particularly in children aged 2-5 years.

Consequently, SAGE has recommended that the vaccine be used only in populations with high seroprevalence $(>80 \%)$ as in high prevalence settings, the vaccine provides overall population benefit. It also suggested that screening individuals for seropositivity prior to vaccination and vaccinating only those who were seropositive is necessary. Consequently, the vaccine is not suitable for the prevention of dengue in travellers unless there is serological evidence of prior infection, and is not currently licensed for use in travellers.

The only way to prevent infection in travellers is to avoid mosquito bites. Recovery from infection provides lifelong immunity against that serotype but confers only partial and transient protection against subsequent infection by the other three serotypes. All travellers to endemic areas should use personal insect protective measures. They should:

- Remain in well-screened or completely enclosed air-conditioned areas.

- Use insect repellent on exposed skin.

- Wear clothing that reduces the amount of exposed skin.

- Use aerosol insecticides indoors.

- Eliminate any standing water in and around the dwelling where Aedes aegypti may breed, such as uncovered water containers, pot plant bases, roof gutters, drains, containers, tyres or depressions in the ground (see also 'Minimising exposure to mosquitoes' in Chap. 3, Sect. 3.2). 


\subsubsection{Hepatitis C}

\section{Organism}

Hepatitis $\mathrm{C}$ virus $(\mathrm{HCV})$ of which there are six main genotypes.

\section{Geographical Distribution}

HCV infects $2 \%$ of the world's population and has a global distribution (Map 5.3), with variation of the distribution of the viral genotypes. The most prevalent genotypes are $1 \mathrm{a}, 1 \mathrm{~b}, 3$ and 4 .

\section{Transmission and Risks to Travellers}

$\mathrm{HCV}$ is a blood-borne virus, and transmission most often involves exposure to the virus through contaminated needles or through the receipt of contaminated blood or blood products. Transmission can also occur infrequently through tattoos, body piercing, sexual activity and perinatally from mother to child. Travellers are generally at low risk, but they should exercise caution with activities that may result in transmission of HCV. These include receiving blood transfusions, having medical or dental procedures, activities such as tattooing, body piercing, acupuncture and injecting drug use. Working in a healthcare setting where there is a potential for exposure to blood may also entail a risk of infection.

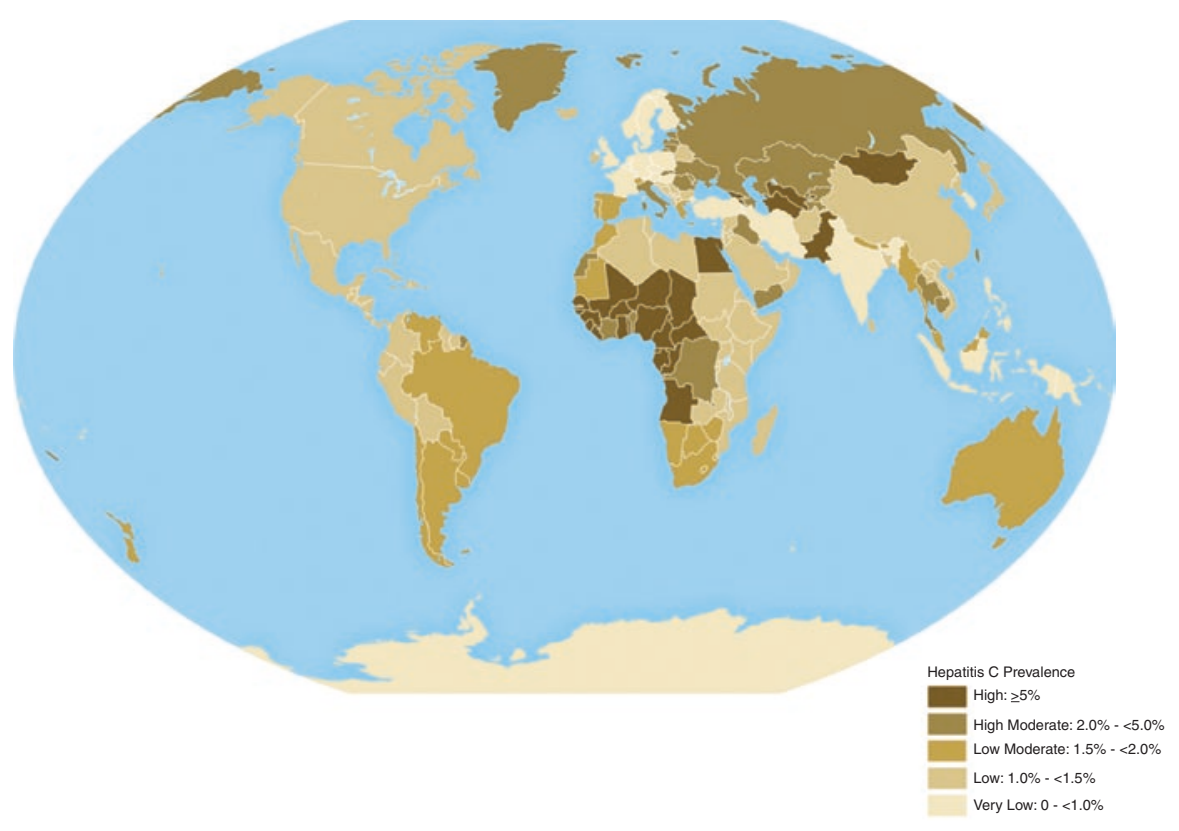

Map 5.3 Global distribution of hepatitis C. Source: https://wwwnc.cdc.gov/travel/yellowbook/2018/infectious-diseases-related-to-travel/hepatitis-c\#5184 


\section{Illness}

The majority of infected individuals are asymptomatic, with only $20 \%$ developing an acute illness with jaundice. If symptoms do develop, they are often non-specific and include malaise, nausea, abdominal discomfort, loss of appetite followed by dark urine and jaundice. Overall, $80 \%$ of infected individuals progress to chronic infection with up to $10 \%$ progressing to cirrhosis of the liver. $\mathrm{HCV}$ is a major cause of both cirrhosis of the liver and hepatocellular carcinoma. The diagnosis relies on both serology for HCV antibodies and nucleic acid amplification to detect HCV RNA in blood. Treatment with directly acting antiviral drugs is now available throughout Europe, the United States, Australia and many parts of the Middle East, South Central and Southeast Asia. Treatment is highly effective with cure achieved in over $95 \%$ if individuals overall.

\section{Prevention}

A vaccine for $\mathrm{HCV}$ is not available, and immunoglobulin has not been shown to be effective in preventing infection. Prevention is therefore based on avoiding activities that are associated with potential exposure to blood or body fluids. In general, travellers should follow similar advice as for the prevention of HIV infection:

- Do not share needles or drug-injecting equipment, and take care when handling, using and disposing of needles or other sharp items.

- Avoid any procedure involving skin penetration, including tattooing, body piercing, shaving, dental work and medical procedures.

- Use condoms correctly with each sexual encounter.

\subsubsection{Hepatitis E}

\section{Organism}

Hepatitis E virus.

\section{Geographical Distribution}

Mainly seen in areas with inadequate environmental sanitation, especially Asia, Africa, the Middle East and Central America (Map 5.4).

\section{Transmission and Risks to Travellers}

Transmitted by the faecal-oral route through drinking contaminated fluids (especially water) and less frequently by eating contaminated food. Hepatitis E is the most common type of acute viral hepatitis in many developing countries and has been responsible for large outbreaks of hepatitis in refugee camps.

\section{Illness}

Clinically indistinguishable from hepatitis A. Complete recovery is the rule, and there is no long-term carrier state. High fatality (15\%) occurs in pregnant women, and foetal loss is common. 


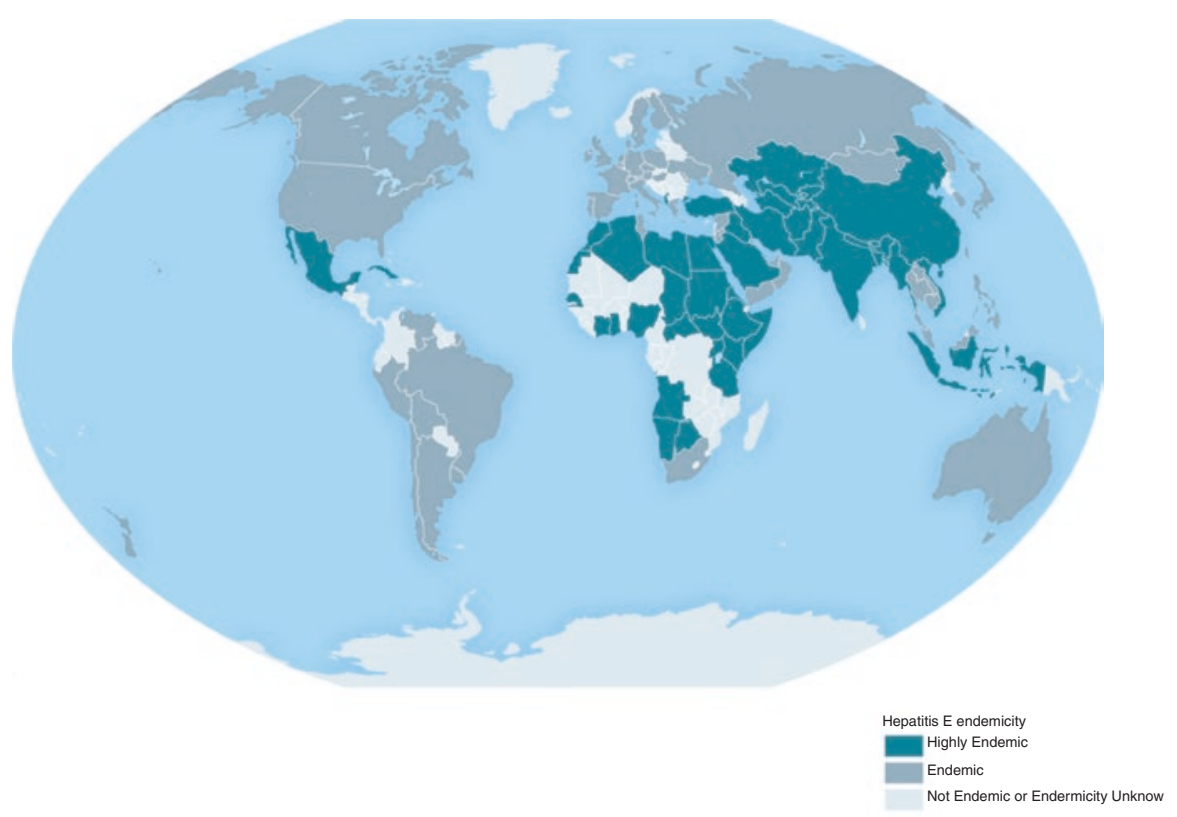

Map 5.4 Global distribution of hepatitis E. Source: https://wwwnc.cdc.gov/travel/yellowbook/2018/infectious-diseases-related-to-travel/hepatitis-e\#5187

\section{Prevention}

- Avoid drinking water (and beverages with ice) of unknown purity.

- Avoid eating uncooked shellfish and uncooked, peeled fruit and vegetables.

\subsubsection{Human Immunodeficiency Virus (HIV)}

\section{Organism}

Human immunodeficiency virus (HIV) types 1 and 2.

\section{Geographical Distribution}

- An estimated 35-40 million people worldwide are living with HIV, although HIV prevalence varies considerably between countries, regions and key populations (see Map 5.5).

- Sub-Saharan Africa remains the most severely affected region, accounting for nearly two-thirds of people living with HIV worldwide.

\section{Transmission and Risks to Travellers}

HIV can be transmitted from an infected person through condomless sexual intercourse, infected blood or blood products and needlestick injuries, and vertically through pregnancy and breastfeeding. Condomless heterosexual intercourse is the 


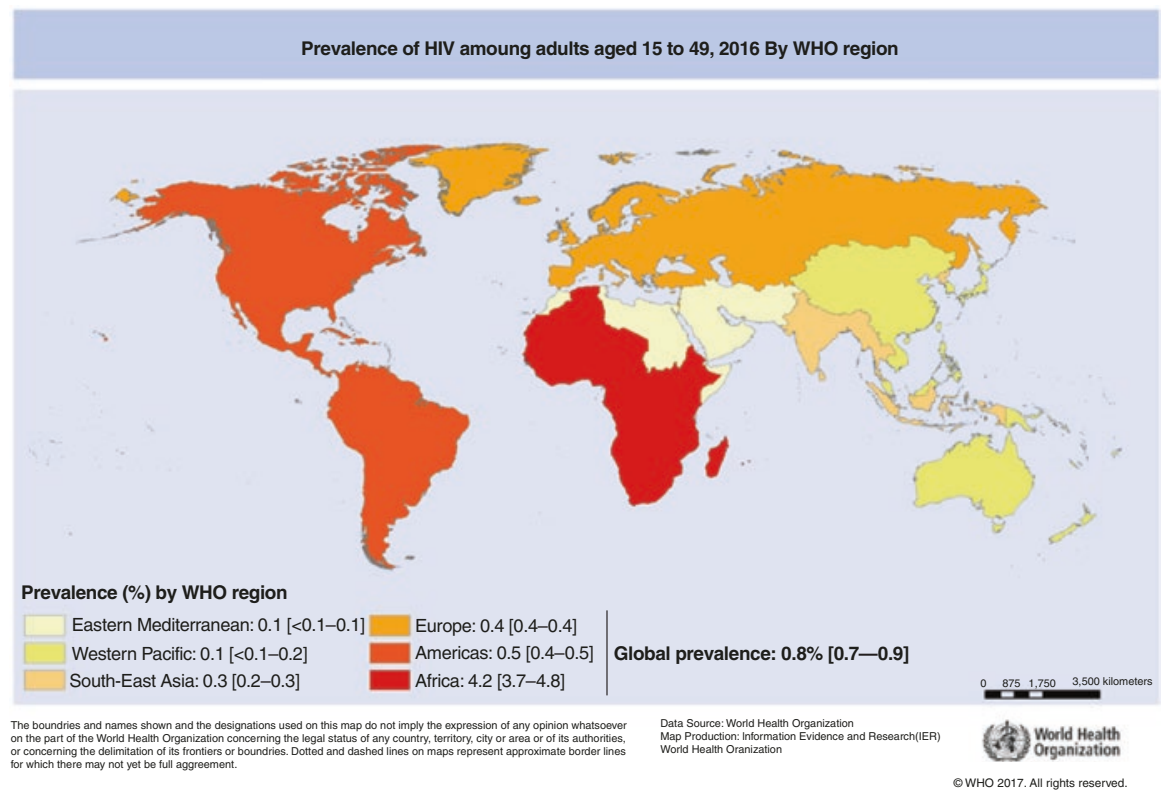

Map 5.5 Estimated prevalence of HIV in people aged 15-49 years. Source: Source: http://www. who.int/gho/hiv/hiv_013.jpg?ua=1

major mode of HIV transmission globally, but transmission dynamics vary significantly between countries and regions. Populations who are more vulnerable to HIV infection include men who have sex with men (MSM), people who inject drugs (PWID), sex workers and transgender people.

Australians travelling overseas face unique risks in relation to HIV. Although they may be travelling to a country with a higher prevalence of HIV or different HIV transmission dynamics, they may assume that behaviour that is low risk in Australia is low-risk overseas. The relative anonymity and absence of social controls during travel, along with consumption of alcohol and/or drugs, may result in disinhibition and lowered concern for safety. Travellers may be unaware of the range of strategies that could reduce their risk of HIV acquisition, including the use of condoms, pre-exposure prophylaxis (PrEP) and post-exposure prophylaxis (PEP). Australians who acquire HIV in the context of travel are at risk of later diagnosis and therefore delayed access to treatment and care.

\section{Illness}

After infection with HIV, some individuals will develop a self-limiting glandular fever-like seroconversion illness, characterised by fever, rash, myalgia, sore throat and swollen lymph nodes. Symptoms typically occur 1-4 weeks after infection and generally resolve within 2-3 weeks; HIV viral loads are very high during seroconversion. Infected people may then be free from clinical signs or symptoms for 
months or years. If HIV infection goes unrecognised and antiretroviral therapy (ART) is not commenced, patients can progress to acquired immunodeficiency syndrome (AIDS). The interval from HIV infection to the diagnosis of AIDS varies widely between individuals but is usually between 10 and 15 years.

\section{Prevention}

- Use condoms correctly with each sexual encounter. Condoms remain the most commonly used HIV/STI prevention method worldwide and, when used successfully, are very effective at preventing HIV transmission. However, real-world effectiveness of condoms is dependent on someone putting one on before sex, keeping it on until the end of the act of sex, and where necessary using appropriate lubricant to prevent condom rupture during sex. These caveats mean that the real-world effectiveness of condoms in preventing HIV is not $100 \%$. Travellers are more likely to use condoms if they bring condoms from home, so encourage patients to pack these in their suitcase.

- Consider prescribing HIV pre-exposure prophylaxis (PrEP) for individuals at medium to high risk of HIV exposure. HIV PrEP involves the use of antiretroviral medication by someone who is HIV negative to reduce the risk of becoming infected with HIV. It is recommended that PrEP be taken every day to minimise HIV risk. HIV PrEP (tenofovir/emtricitabine 300/200 mg) is now available on the Australian PBS. Resources for HIV PrEP are listed at the end of this chapter.

- Do not share needles or drug-injecting equipment, and take care when handling, using and disposing of needles or other sharp items.

- Avoid any procedure involving skin penetration, including tattooing, body piercing, shaving, dental work and medical procedures.

\section{Management of Potential Exposures}

The risk of HIV transmission through a single exposure is determined by a range of factors including:

- The nature of the exposure

- The risk that the source is HIV positive if their status is unknown

- The HIV viral load of the source if known to be HIV positive (higher plasma viral load is associated with increased risk of HIV transmission)

- The presence of a sexually transmitted infection (STI) or breach in genital or oral mucosal integrity in the source or exposed individual if the exposure is sexual in nature

All travellers should be made aware of the existence of HIV post-exposure prophylaxis (PEP). HIV PEP consists of a 28-day course of combination antiretroviral medication and has been shown to be effective in preventing HIV infection if started within $72 \mathrm{~h}$ of an exposure. The key to PEP is accessing it as soon as possible after a possible exposure to HIV. PEP is not universally available, so it may be appropriate to prescribe a course of PEP for some groups of travellers, such 
as medical students undertaking electives or healthcare workers volunteering in countries with high HIV prevalence. In Australia, PEP can only be prescribed by an S100 prescriber.

All travellers who report engaging in risk behaviours during travel (such as condomless sex, procedures involving skin penetration and recreational drug use) should be encouraged to undergo HIV testing (along with testing for other bloodborne viruses and STIs where appropriate). To ensure the individual is HIV negative, HIV testing must be performed (or repeated) at least 6 weeks after the last potential exposure has occurred.

\subsubsection{Legionellosis (Legionnaires' Disease)}

\section{Organism}

Various Legionella species, particularly L. pneumophila.

\section{Geographical Distribution}

Worldwide distribution. Many cases are acquired in Europe, particularly around the southern Mediterranean.

\section{Transmission and Risks to Travellers}

Transmission is via the airborne route. Travel is emerging as a strong risk factor for the acquisition of Legionnaires' disease. Individuals staying in resort hotels and on cruise ships or using spa facilities are at highest risk.

\section{IIIness}

Initial stage characterised by fever, anorexia, diarrhoea, malaise, myalgia, headache and nonproductive cough. Can progress to respiratory failure.

\section{Prevention}

- Monitoring and cleaning of cooling towers and water systems is recommended to decrease the risk of disease acquisition.

\subsubsection{Leishmaniasis (Cutaneous and Visceral)}

\section{Organism}

Various Leishmania species.

\section{Geographical Distribution}

Leishmaniasis can be classified geographically into New World (Central/South America) and Old World diseases. Leishmania organisms are endemic in scattered foci in $>80$ countries on every continent except Australia, Oceania and Antarctica. More than $90 \%$ of cutaneous infections occur in the Middle East, Saudi Arabia, Iran, Peru, Afghanistan and Brazil. More than $90 \%$ of visceral infections occur in 
Bangladesh, India, Sudan and Brazil. Infections also occur in southern Europe, particularly in Spain, Italy and southern France.

\section{Transmission and Risks to Travellers}

Transmitted by sand flies, which usually are most active from dusk to dawn, leishmaniasis occurs predominantly in individuals living in endemic regions, but travellers to these areas can also be infected, even after $<1$ week of exposure. Leishmaniasis is more common in rural than urban areas.

\section{Illness}

Clinical findings can be divided into cutaneous, mucocutaneous or visceral manifestations. Cutaneous lesions can have a wide range of appearances but typically cause either 'wet' or 'dry' ulcers. In visceral leishmaniasis, splenomegaly, fever and cachexia are common. Many infections are asymptomatic.

\section{Prevention}

In endemic areas, preventive measures include vector control, control of animal reservoirs and early diagnosis and treatment of cases. No vaccine or chemoprophylaxis is available.

In travellers, personal protective measures against sand fly bites are most effective:

- Avoid outdoor activities, especially from dusk to dawn.

- When outside, wear long-sleeved shirts, long pants and socks.

- Apply insect repellents on uncovered skin.

- Spray clothing with permethrin-containing insecticides.

- Use a bed net if sleeping in an unscreened room.

\subsubsection{Leptospirosis}

\section{Organism}

Spirochete, Leptospira interrogans.

\section{Geographical Distribution}

Worldwide, but mainly in the tropics.

\section{Transmission and Risks to Travellers}

Transmitted when skin or mucous membranes come into contact with water, moist soil or vegetation contaminated with urine of infected animals or rodents. Occupational hazard for field workers, farmers, abattoir workers and others who have contact with urine or tissues of contaminated animals. Travellers who bathe, wade or raft in contaminated waters are at potential risk. An outbreak occurred in athletes participating in Eco-Challenge-2000 in Borneo, Malaysia. Hiking in jungle areas during the rainy season is also high risk for exposure. 


\section{Illness}

Typically a biphasic illness characterised by fever, headache, abdominal pain, severe myalgia and conjunctival suffusion. It can be complicated by meningitis, vasculitis, nephritis, hepatitis, myositis, conjunctivitis, myocarditis, arthritis, haemorrhage, respiratory distress and confusion. The time between exposure and symptom onset is 2 days to 4 weeks.

\section{Prevention}

- Avoid recreational water activities such as swimming or wading in endemic areas.

- Wear protective clothing.

- There is no vaccine available for travellers.

- Doxycycline prophylaxis (200 mg weekly beginning 1-2 days before exposure and continuing through the period of exposure) can be considered for those at high risk but is rarely indicated.

\subsubsection{Lyme Disease}

\section{Organism}

Borrelia burgdorferi, a Gram-negative spirochaete (spiral-shaped bacteria).

\section{Geographical Distribution}

Clinically confirmed cases of Lyme disease have been reported all over Eurasia, as well in the United States and Canada. It is the most commonly reported tick-borne infection in Europe and North America. The abundance of reservoir hosts (usually small- and medium-sized animals) in a particular habitat is the most important factor in the establishment of significant infected tick populations.

\section{Transmission and Risks to Travellers}

It is transmitted during the blood feeding of ticks of the genus Ixodes. Ticks thrive in conditions found in temperate deciduous woodland, so disease can occur in hikers or campers. Tick activity is greatest in spring and early summer.

\section{IIIness}

Infection can be subclinical (asymptomatic) or have a range of clinical presentations. Clinical presentations can generally be divided into three stages, but progression from an early to later stage is not inevitable, even if the infection is untreated.

1. Early localised Lyme borreliosis: Over $60 \%$ of cases develop erythema migrans, a characteristic red rash or lesion spreading from the site of a tick bite. The affected patient may also have vague 'flu-like' symptoms.

2. Early disseminated Lyme borreliosis: The organism may spread to other tissues via the bloodstream and lymphatics. Manifestations of this stage include multiple 
areas of erythema migrans (usually smaller than the initial lesion), facial palsy, cranial nerve lesions, aseptic meningitis, encephalitis, arthritis and carditis.

3. Late Lyme borreliosis: Progression to this stage is uncommon but may occur in patients who were not treated or inadequately treated at an earlier stage. The most frequent manifestations include chronic arthritis, acrodermatitis chronica atrophicans (widespread atrophy of the skin) and meningoencephalitis.

\section{Prevention}

- Avoid walking or camping in wooded areas during spring/summer.

- Promptly remove an attached tick if you notice it.

- Prophylactic treatment with an antibiotic is not recommended for a tick bite.

- A vaccine was produced but is no longer manufactured and is not available.

\subsubsection{Lymphatic Filariasis, Loiasis and Onchocerciasis}

\section{Organism}

Lymphatic filariasis is caused by one of three lymphatic-dwelling filarial parasites, namely, Wuchereria bancrofti, Brugia malayi or Brugia timori. Loiasis is caused by the parasite Loa loa. Onchocerciasis is caused by the parasite Onchocerca volvulus.

\section{Geographical Distribution}

W. bancrofti occurs in Sub-Saharan Africa, Southeast Asia, the Indian subcontinent, many of the Pacific Islands and focal areas in Latin America. $B$. malayi occurs mainly in China, India, Malaysia, the Philippines, Indonesia and various Pacific Islands. B. timori is limited to the island of Timor (Indonesia and East Timor). Loiasis is limited to rainforests of West and Central Africa. Onchocerciasis is limited to rural areas of tropical Africa (particularly in Nigeria and Democratic Republic of Congo), the Arabian Peninsula (Yemen) and Latin America (Brazil and Venezuela). Within endemic regions, the infection has a focal distribution that coincides with areas conducive to breeding sites for the mosquito vector.

\section{Transmission and Risks to Travellers}

Lymphatic filariasis is spread by the bite of a mosquito harbouring infective larvae. Loiasis is transmitted by deerflies or horseflies. Onchocerciasis is transmitted by the bite of a blackfly. These infections are very rare in short-term travellers $(<3$ months), but the risk increases with length of stay.

\section{Illness}

Most infections are asymptomatic. Specific syndromes associated with lymphatic filariasis include acute adenolymphangitis, filarial fever and tropical pulmonary eosinophilia. Lymphatic obstruction may lead to permanent changes of elephantiasis, but this occurs mainly in individuals from endemic areas with high worm burdens, 
not in travellers. Infected travellers instead may demonstrate an allergic-type reaction to developing larvae that is characterised by a local eosinophilic infiltrate, causing lymphangitis, lymphadenitis, urticaria and rash. Loiasis causes episodic swellings ('Calabar swellings') or subconjunctival migration of the adult worm. Onchocerciasis in travellers generally causes a non-specific dermatitis that can be intensely itchy. Ocular and skin complications are very rare, except in natives of endemic regions.

Marked peripheral eosinophilia is a feature of these diseases in travellers (may exceed $3000 / \mu \mathrm{L})$.

\section{Prevention}

Protection against insect bites is most important.

- Sleep under a mosquito net.

- Use mosquito repellent on exposed skin between dusk and dawn.

- Diethylcarbamazine $300 \mathrm{mg}$ taken once a week during the period of risk is effective in preventing filarial infection but is not recommended for travellers.

- In endemic areas, prevention relies on vector control and mass chemotherapy programmes.

\subsubsection{Melioidosis}

\section{Organism}

Burkholderia pseudomallei.

\section{Geographical Distribution}

Mostly found in Southeast Asia, particularly in Thailand. Also occurs in northern Australia, South America and West Africa. The organism has a widespread distribution in soil, stagnant water and rice paddies in endemic areas.

\section{Transmission and Risks to Travellers}

Infection is acquired via contact of broken skin with contaminated soil, via aspiration or ingestion of contaminated water or via inhalation of dust from soil. Infection in short-term travellers is uncommon.

\section{Illness}

Infection may be asymptomatic, lead to isolated skin or pulmonary disease, cause meningoencephalitis or be disseminated and cause multi-organ involvement and overwhelming sepsis. Typical respiratory symptoms are cough, chest pain and occasionally haemoptysis. Chronic abscesses and osteomyelitis can result. Diabetics, people who abuse alcohol and the immunosuppressed are at greatest risk of symptomatic infection. Reactivation of latent infection can occur, with progressive immunosuppression. 


\section{Prevention}

Avoid exposure to soil and rice paddies in endemic areas, especially if diabetic, immunosuppressed or open wounds are present. Wear shoes when outdoors.

\subsubsection{MERS (Middle Eastern Respiratory Syndrome)}

\section{Organism}

MERS is a respiratory infection caused by a coronavirus, called MERS.

\section{Geographical Distribution}

MERS was first reported in 2012. Infections have occurred in people who have travelled to or lived on the Arabian Peninsula, especially Saudi Arabia, which accounts for approximately $80 \%$ of human cases. Other countries in which the virus has been identified in dromedary camels include Egypt, Oman and Qatar. Cases have also been exported by travellers, including a large outbreak in the Republic of Korea in 2015.

\section{Transmission and Risks to Travellers}

Dromedary camels appear to be the primary animal host for MERS and the source of many infections in humans. Bats may also act as a reservoir. However most cases are acquired through human-to-human transmission and are usually associated with outbreaks in healthcare settings. Possible modes of transmission are via droplets and direct contact with secretions, and there is the potential for secondary spread to household contacts. Although the exact route(s) of transmission from camels are unknown, it is thought to occur via contact with infectious bodily secretions and by consumption of raw dromedary products.

All cases of MERS reported outside of the Arabian Peninsula have occurred in travellers, or as a result of secondary transmission from a patient with recent travel to the Arabian Peninsula.

\section{IIIness}

MERS has an incubation period of 2-14 days (median of 5 days). Initial symptoms are similar to other viral respiratory infections and include fever, runny nose, cough and shortness of breath. Cases can be asymptomatic or cause mild respiratory symptoms, but rapid progression to severe pneumonia, acute respiratory distress syndrome, acute kidney injury and gastrointestinal symptoms (vomiting and diarrhoea) can develop. Some patients develop pericarditis and disseminated intravascular coagulation. Chest X-rays are abnormal in all cases. Severe disease occurs most often in those aged over 50 years and with comorbidities, such as heart disease, diabetes, chronic renal failure, chronic lung disease, malignancy or immunosuppression. Approximately one third of laboratory-confirmed cases have been fatal. 


\section{Prevention}

No specific therapy for MERS exists; treatment is supportive and based on the patient's clinical condition. No vaccine is currently available.

Anyone visiting farms, markets, barns or other places where dromedary camels and other animals are present on the Arabian Peninsula should practice general hygiene measures, including regular handwashing or use of a hand sanitiser before and after touching animals. Close contact with sick people or animals should be avoided. In addition, it is advised to avoid camel urine or drinking raw camel milk and to avoid eating camel meat that has not been cooked thoroughly. Furthermore, patients at high risk of severe disease should avoid contact with camels.

In the setting of healthcare facilities, infection prevention measures are critical to prevent the possible spread of MERS. Reduce transission risks if providing care for patients suspected or confirmed with MERS via isolation in a single room (preferably negative pressure room if available), using contact precautions and giving the patient or visitors a surgical mask to wear.

\subsubsection{Myiasis (Cutaneous)}

\section{Organism}

Two species of fly that cause cutaneous myiasis are Cordylobia anthropophaga (tumbu fly) and Dermatobia hominis (botfly).

\section{Geographical Distribution}

The tumbu fly exists throughout Sub-Saharan Africa. The human botfly is endemic throughout Central and South America.

\section{Transmission and Risks to Travellers}

Larvae of both species can attach to and penetrate the intact skin of healthy hosts, producing furuncles.

\section{Illness}

The tumbu fly skin lesion starts as a papule, which may be itchy or pricking. As the papule grows, the lesion resembles a boil. After 8-12 days, larvae emerge from the skin. Lesions may involve any part of the body but usually occur on the back, head or neck.

The botfly skin lesion begins as a pruritic erythematous papule, which appears within $24 \mathrm{~h}$ of infestation. As larvae develop subdermally over 6-12 weeks, lesions enlarge with local inflammatory reaction and increasing local symptoms. When mature larvae work their way to the skin, significant local pain can develop, and movement can be sensed within the skin.

Both types of larvae can be induced to emerge from the skin by covering the lesion with an occlusive material (e.g. paraffin oil or Vaseline) to restrict the oxygen supply. 


\section{Prevention}

Prevention of tumbu fly infestation:

- Avoid playing or sleeping on the ground.

- Dry clothes indoors with the window closed or screened to prevent contact with flies.

- Iron all clothing, sheets and towels with a hot iron on both sides to kill emerging larvae.

Prevention of botfly infestation:

- Avoid insect bites by using personal protection measures, repellents and clothing.

\subsubsection{Q Fever}

\section{Organism}

Coxiella burnetii.

\section{Geographical Distribution}

Occurs on all continents. Animal reservoirs are cattle, sheep and goats.

\section{Transmission and Risks to Travellers}

Transmission is generally by airborne dissemination of organisms in dust, so the disease can occur in people without direct animal contact. Direct contact with contaminated straw, wool, hair and hides can also transmit Q fever. Raw milk from infected cows contains organisms and may be another source of infection.

Q fever is mainly an occupational disease of the meat industry and of farmers. Disease in travellers is uncommon, but travellers can contract the infection through direct or indirect contact with animals, e.g. visiting farms or attending agricultural shows.

\section{IIIness}

Q fever can present as an acute febrile illness or as a chronic relapsing disease. The chronic form usually presents as a chronic relapsing febrile illness although rarely may present as a culture-negative endocarditis.

\section{Prevention}

- Avoid animal contact.

- An effective vaccine is available for those at occupational risk, but is not recommended for travellers. 


\subsubsection{Rickettsial Infections}

\section{Spotted Fevers}

\section{Organism}

Examples include Rickettsia rickettsii (Rocky Mountain spotted fever), Rickettsia conorii (Mediterranean spotted fever), Rickettsia africae (African tick bite fever) and Rickettsia australis (Queensland tick typhus).

\section{Geographical Distribution}

$R$. rickettsii is present throughout the United States and also in Mexico and South America. $R$. conorii is present in Africa, India, the Mediterranean region and the Middle East. $R$. africae is present in Sub-Saharan Africa (especially Botswana, Zimbabwe and South Africa). $R$. australis is present in Queensland, New South Wales, Tasmania and eastern Victoria.

\section{Transmission and Risk to Travellers}

Transmitted by tick bites. Occasionally occurs in travellers who spend time trekking or camping, or on safari in grassy areas where ticks are prevalent.

\section{Illness}

Fever, malaise, myalgia, headache and maculopapular rash are typical. Often there is an eschar at the site of the tick bite.

\section{Prevention}

- Avoid tick bites by using repellents and wearing protective clothing.

- If exposed, prompt detection and tick removal is important.

\section{Typhus Group}

\section{Organism}

Rickettsia prowazekii (epidemic typhus), Rickettsia typhus (murine typhus).

\section{Geographical Distribution}

$R$. prowazekii is worldwide. $R$. typhi is also worldwide, but in focal areas.

\section{Transmission and Risk to Travellers}

$R$. prowazekii is spread by the body louse. It tends to occur in epidemics, associated with poor hygiene and in impoverished populations. $R$. typhus is spread by rat fleas and often occurs following exposure to rat-infested buildings. Neither is seen commonly in travellers.

\section{Illness}

Headache, fever, myalgia, lymphadenopathy and macular rash are common. 


\section{Prevention}

- Avoid vector-infested habitats.

- Use repellents and wear protective clothing when exposed.

\section{Scrub Typhus}

\section{Organism \\ Orientia tsutsugamushi.}

\section{Geographical Distribution}

O. tsutsugamushi exists in the South Pacific, Papua New Guinea, Southeast Asia and East Asia, including China, Korea and Japan, and tropical northern Australia (Kimberley region of Western Australia, Top End of the Northern Territory, especially Litchfield Park, coastal northern Queensland north of Townsville and the Torres Strait Islands).

\section{Transmission and Risks to Travellers}

Scrub typhus is transmitted by mites. The larval form of the mite lives in grass and attaches to passing humans or animals. The mite goes unnoticed because of its small size. Disease occurs in people who engage in outdoor occupational or recreational activities and so can be seen in travellers who hike or camp in grassy areas.

\section{Illness}

Abrupt onset of fever, lethargy, myalgia, cough, photophobia, headache, vomiting and conjunctivitis. Maculopapular rash $(50 \%)$ occurs 7 days after the onset of the illness. An eschar is often present with associated lymphadenopathy.

\section{Prevention}

- Avoid vector-infested habitats.

- Use repellents and wear protective clothing.

\subsubsection{SARS (Severe Acute Respiratory Syndrome)}

\section{Organism}

Caused by a coronavirus, called the SARS-associated coronavirus (SARS-CoV).

\section{Geographical Distribution}

SARS was first reported in Asia in February 2003. Over the next few months, the illness spread to more than two dozen countries in North America, South America, Europe and Asia before the outbreak was contained. The countries most heavily affected included China, Hong Kong, Vietnam, Taiwan, Singapore, the Philippines and Canada. No cases have been reported since 2004 . 


\section{Transmission and Risks to Travellers}

SARS is mainly spread by respiratory droplets produced when an infected person coughs or sneezes on someone in close proximity. The virus can also spread when a person touches a surface or object contaminated with infectious droplets. Airborne spread might also be possible. Given there are no cases of SARS since 2004, there is no risk to travellers.

\section{Illness}

SARS is a viral respiratory illness that generally begins with a high fever. Possible associated symptoms include headache, malaise and myalgia. Some people have mild respiratory symptoms at the outset. Rash and neurologic or gastrointestinal findings are generally absent, although 10-20\% of patients have reported diarrhoea during the febrile prodrome. After 2-7 days, patients may develop a dry cough or shortness of breath. Most patients develop pneumonia, and about $10-20 \%$ of cases require mechanical ventilation because of hypoxia.

\section{Prevention}

Careful and frequent handwashing is most important for preventing infection. Travellers to areas reporting SARS cases should avoid settings where SARS is most likely to be transmitted, such as healthcare facilities caring for SARS patients. The routine use of masks or other personal protective equipment while in public areas is not recommended.

\subsubsection{Schistosomiasis ('Bilharzia')}

\section{Organism}

Caused by parasites (blood flukes) known as schistosomes. There are five species of schistosomes that infect humans: Schistosoma mansoni, S. haematobium, S. japonicum, S. mekongi and S. intercalatum. The first two species are the most prevalent. The parasite species differ in snail host, global distribution, egg morphology, preferred location of residence in the host and pathophysiology.

\section{Geographical Distribution}

At least 200 million people around the world are infected with schistosomiasis. $S$. mansoni and S. haematobium are distributed throughout Africa; S. haematobium is also found in areas of the Middle East, and S. mansoni is present in some parts of South America and the Caribbean. S. japonicum is found in Indonesia and parts of China and Southeast Asia, S. mekongi is found in Cambodia and Laos, and S. intercalatum is found in parts of Central and West Africa (see Map 5.6).

\section{Transmission and Risk to Travellers}

Transmission is via skin contact with contaminated freshwater in which live certain types of snails that are essential to maintain the parasites' life cycle. Parasites leave the snail as cercariae and penetrate unbroken skin of individuals in contact with water. 


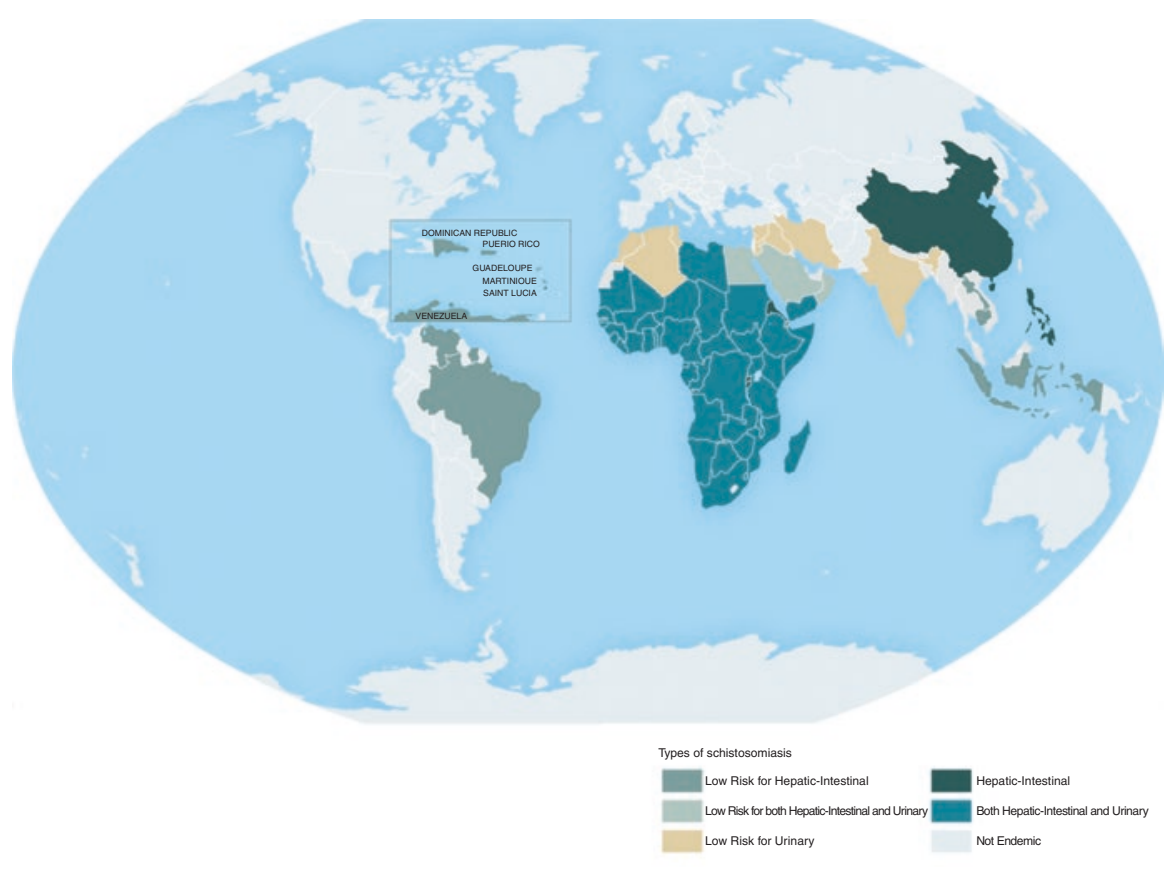

Map 5.6 Global distribution of schistosomiasis. Source: https://wwwnc.cdc.gov/travel/yellowbook/2018/infectious-diseases-related-to-travel/schistosomiasis\#5262

In Australia, schistosomiasis occurs only as an imported infection in returned travellers or immigrants. The majority of travel-associated infections occur in people who have visited Africa, and the risk occurs in people who have contact with contaminated freshwaters, including rivers, streams and lakes. Areas that pose a particularly high risk include the Nile Valley, Lake Malawi, Lake Victoria, the Tigris and Euphrates river systems, and artificial lakes such as Lake Kariba in Zimbabwe and Lake Volta in Ghana. The risk of infection for travellers who swim in infected waters is of the order of $10 \%$. Even brief exposure to contaminated water can result in infection.

\section{Illness}

Schistosomiasis infection is usually asymptomatic but can be associated with symptoms related either to acute infection or chronic complications.

1. Acute presentations: Travellers in particular may have a brisk immune response following exposure to the parasite and within days of being infected may develop a rash or itchy skin where the larvae have entered the body (cercarial dermatitis), which resolves spontaneously. Within 1-2 months, fever, chills, cough and muscle ache may develop (Katayama fever). Eosinophilia is a common feature. 
2. Chronic complications: The chance of developing chronic sequelae of schistosomiasis increases with high parasite and egg burdens. Complications include portal hypertension, cor pulmonale, intestinal schistosomiasis, fibrosis of the bladder and ureters with secondary obstruction, calcification and malignancy within the urinary tract and bladder.

3. Neurological complications: Unlike most chronic complications of schistosomiasis, neurological sequelae can occur in individuals with minimal worm burden and therefore can be a problem for travellers. It is mainly because of the potential risk of neurological sequelae that screening and treatment is recommended for travellers who may have been exposed. Spinal schistosomiasis is most commonly seen and can be associated with paraplegia. Cerebral involvement with seizures, confusion and coma may also occur.

\section{Prevention}

There is no easy way to determine if water in endemic countries is contaminated with schistosomiasis, so travellers are advised to avoid swimming or wading in freshwater. Swimming in salt water (ocean or seas) or in chlorinated swimming pools is safe.

Ways to reduce the risk of infection include:

- Swim for short periods in flowing, rather than still, water.

- Avoid swimming during the early and late parts of the day.

- Vigorously rub oneself down with a towel immediately after leaving the water. Larvae die quickly on removal from water and cannot survive drying, so quick drying of exposed skin and clothing may offer some protection against infection.

- There is no vaccine available at present, and available drugs are not known to be effective as chemoprophylactic agents.

\subsubsection{Strongyloidiasis}

\section{Organism}

Strongyloides stercoralis.

\section{Geographical Distribution}

Found mainly in tropical and subtropical areas, but cases also occur in temperate areas. It is more frequently found in rural areas.

\section{Transmission and Risk to Travellers}

Infective filariform larvae, which are passed in faeces or develop in faecally contaminated soil, penetrate directly through the skin when contacting infected soil.

\section{Illness}

Infection is frequently asymptomatic. Clinical manifestations may include transient dermatitis following initial skin penetration, recurrent urticarial rash (larva currens), 
eosinophilic pneumonia or gastrointestinal symptoms with abdominal pain and/or diarrhoea. Blood eosinophilia is generally present during the acute and chronic stages.

Unlike most helminths, which cannot replicate within a human host, strongyloides infection can result in an 'autoinfection' cycle, and the burden of adult worms can increase substantially without ongoing exposure. This autoinfection cycle also enables the organism to persist for decades and cause clinical manifestations long after the initial infection. In immunosuppressed patients, disseminated strongyloidiasis can occur, with abdominal pain, distension, shock, pulmonary and neurologic complications and septicaemia. Disseminated infection is potentially fatal.

Exclusion of strongyloidiasis in those potentially exposed, and adequate treatment while a person is asymptomatic or mildly symptomatic, has the potential to prevent life-threatening complications.

\section{Prevention}

- Use footwear in endemic areas, and try to avoid direct contact of skin with soil.

\subsubsection{Viral Haemorrhagic Fevers}

\section{Organism}

Multiple viruses including arenaviruses (Junin, Machupo, Guanarito, Lassa); bunyaviruses (including Congo-Crimean, Rift Valley fever); flaviviruses (including yellow fever, dengue haemorrhagic fever); and filoviruses (Marburg and Ebola).

\section{Geographical Distribution}

Multiple different viruses exist in different geographical areas. Most types exist in Africa, the Middle East or South America.

In 2014-2016, there was a major epidemic of Ebola in West Africa (mainly affecting Liberia, Sierra Leone and Guinea) that infected more than 29,000 people and caused 11,000 deaths. More recent outbreaks are occurring in the Democratic Republic of Congo (DRC). As of September 2019 there have been 2980 confirmed and 111 probable cases of Ebola in DRC, with an overall case fatality rate of $67 \%$.

\section{Transmission and Risks to Travellers}

Most are spread by mosquitoes, ticks or rodents. Congo-Crimean, Lassa, Marburg and Ebola can also be spread from person to person. Apart from dengue (discussed separately above), most are very rare in travellers.

Epidemics of Ebola virus disease are generally thought to begin when an individual becomes infected via contact with the tissues or body fluids of an infected animal (likely apes). Once the patient becomes ill or dies, the virus then spreads to others who come into direct contact with the infected individual's blood, skin, or other body fluids.

\section{Illness}

Often associated with fever, bleeding and shock. These should be considered in febrile travellers who have returned from an endemic area where active disease transmission 
has been reported. All have incubation periods of up to 2-3 weeks, so it may be possible to exclude viral haemorrhagic fever on epidemiological grounds alone. Ebola is also often associated with headache, vomiting, diarrhoea, rash and conjunctival injection.

\section{Prevention}

1. Avoid contact with associated vectors, including mosquito (precautions described in Sect. 3.2).

2. Yellow fever vaccine if travelling to an endemic area.

3. For Ebola, avoid direct contact without PPE with people who are ill or have died of the disease. Ensure bush meat is properly cooked prior to eating. For those who have had the disease, as transmission can occur sexually, it is recommended to practice safe sex for at least 12 months from the onset of infection.

\subsubsection{West Nile Fever}

\section{Organism}

West Nile virus is a flavivirus closely related to Japanese encephalitis, Kunjin, Murray Valley encephalitis and St. Louis encephalitis virus. The virus can infect humans, birds, mosquitoes, horses and some other mammals.

\section{Geographical Distribution}

It is commonly found in Africa, West Asia and the Middle East. West Nile virus first appeared in North America in 1999, with encephalitis reported in humans and horses. It is now permanently established in the western hemisphere.

\section{Transmission and Risks to Travellers}

West Nile virus is spread by the bite of an infected Culex mosquito. It does not spread from person to person or from animal to person. West Nile virus is amplified during periods of adult mosquito blood feeding by continuous transmission between mosquito vectors and bird reservoir hosts. People, horses and most other mammals are not known to develop infectious-level viraemia very often and thus are probably 'dead-end' or incidental hosts.

In the temperate zone of the world (i.e. between latitudes $23.5^{\circ}$ and $66.5^{\circ}$ north and south), West Nile encephalitis cases occur primarily in the late summer or early autumn. In the southern climates where temperatures are milder, West Nile virus can be transmitted year-round.

\section{Illness}

Most West Nile virus infections are mild and often clinically unapparent. The incubation period ranges from 3 to 14 days. Approximately 20\% of those infected develop a self-limiting mild febrile illness with headache and rash (West Nile fever).

Approximately 1 in 150 infections will result in severe neurological disease with encephalitis, meningitis ataxia and extrapyramidal signs, optic neuritis, cranial nerve abnormalities, severe muscle weakness and flaccid paralysis, polyradiculitis, 
myelitis and seizures. The most significant risk factor for developing severe neurological disease is advanced age.

\section{Prevention}

- Reassure travellers that human illness from West Nile virus is rare, even in areas where the virus has been reported, and the chance of a mosquito bite leading to an illness is low.

- Advise travellers that they can further reduce the risk by protecting themselves from mosquito bites (as described in Sect. 3.2).

\subsubsection{Zika Virus}

\section{Organism}

Zika virus (ZIKV), a flavivirus.

\section{Geographical Distribution}

Zika virus was first isolated in humans in Africa in the 1950s, and in Asia in the 1960s, but remained relatively unknown until it crossed the Pacific Ocean in a serious of explosive outbreaks starting in Micronesia (2007), followed by the Pacific Islands (2013-2016) and the Americas (2015-2017) (Map 5.7). More than 85 countries, territories or subnational areas in Africa, the Americas, Southeast Asia and the Western Pacific have reported evidence of vector-borne ZIKV transmission, and as many as 60 other countries (including Australia) have an established competent vector, but no documented reports of local vector-borne transmission.

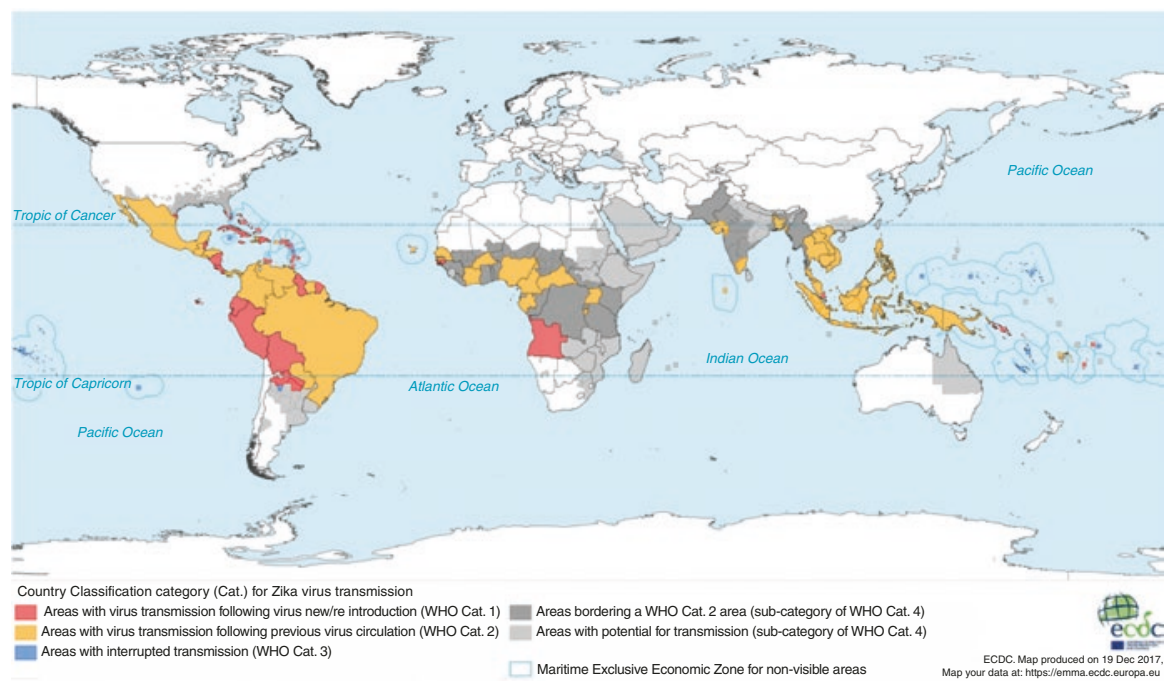

Map 5.7 Global distribution of Zika virus. Figure: Current Zika transmission worldwide, December 2017. Source: ECDC https://ecdc.europa.eu/en/publications-data/current-zika-transmission-worldwide 


\section{Transmission and Risks to Travellers}

Although the primary mode of Zika transmission is via the bite of the Aedes mosquito (Aedes aegypti and Aedes albopictus), Zika can also be transmitted from person to person both horizontally through sexual transmission and vertically from the mother to foetus during pregnancy. Transmission has also been reported following blood transfusion. Suspected nonsexual transmission following close contact with body fluids from a patient with fulminant Zika infection has been documented in a single case report.

ZIKV RNA has been detected in a number of body fluids including semen, urine, saliva, cerebrospinal fluid, amniotic fluid and vaginal and cervical secretions. ZIKV appears to remain in semen longer than in other body fluids, with reports of detectable ZIKV RNA in semen up to 9 months after onset of symptoms. However, there are shortcomings to using molecular (RNA) detection of ZIKV to estimate transmissibility, as detection of the genetic material of the virus does not necessarily equate to the presence of infectious virus. A recent study of men with symptomatic ZIKV infection showed that shedding of potentially infectious ZIKV (determined by viral culture) was limited to the first few weeks after illness onset; the longest reported period of detection for infectious ZIKV in the literature is 69 days after illness onset. Sexual transmission from both asymptomatic and symptomatic cases may follow unprotected male-to-female, male-to-male and female-to-male sex. Sexual transmission has been reported to occur up to 44 days after symptom onset in the source patient.

The rates of vertical transmission and congenital infection following ZIKV infection in pregnancy have not yet been clearly established, and the full range of disabilities (including the possible effect on neurodevelopment) remains unknown. The reported risk of recognisable congenital neurologic defects related to ZIKV following infection in pregnancy is $5-10 \%$. Congenital defects may occur following infection in any trimester, but the risk is highest when infection occurs during the first trimester.

\section{Illness}

Approximately $80 \%$ of ZIKV infections are asymptomatic. When illness occurs, it follows a short incubation period of 2-7 days and is generally mild and self-limited; common symptoms include fever, rash, pruritis, arthralgia, myalgia, conjunctivitis and headache. ZIKV infection has been associated with an increased risk of neurologic complications including Guillain-Barre syndrome. Adverse pregnancy outcomes including stillbirth and miscarriage can occur following ZIKV infection during pregnancy, and congenital neurologic defects reported in infants born to mothers infected during pregnancy include microcephaly, neurologic and ocular defects.

\section{Prevention}

There is no vaccine for Zika virus. All travellers to Zika endemic areas should be advised to avoid being bitten by mosquitoes and be counselled on measures to prevent sexual and vertical transmission.

Pregnant women living in areas free of Zika risk should be advised not to travel to Zika-affected areas during outbreaks. If travel cannot be avoided, in addition to 
advice about mosquito bite prevention, they should be advised to use male or female condoms during any sexual activity (including vaginal, anal and oral sex and sharing of sex toys) for the duration of their pregnancy.

For individuals or couples who are considering or planning pregnancy, it is recommended that:

- Women travelling to a Zika-affected country, or who are diagnosed with Zika infection, should avoid unprotected sex and pregnancy during travel and for at least 8 weeks after return, or 8 weeks after diagnosis.

- Men with a female partner who are travelling to a Zika-affected country, or who are diagnosed with Zika infection, should avoid unprotected sex during travel and for up to 6 months after return, or 6 months after diagnosis. Recommended waiting periods vary: the CDC currently recommends 3 months, whereas the WHO and Australian Department of Health recommend 6 months.

- Couples who are planning a pregnancy should be offered advice about the availability of serological testing, which can be performed 4 weeks or more after return to help exclude Zika virus exposure, particularly if there are concerns about the consequences of delaying pregnancy for the above recommended time periods.

To minimise the risk of sexual transmission, all travellers should be advised to avoid unprotected sex:

- During travel and for up to 6 months after the last day in a Zika-affected country, or from the time of diagnosis of infection, for males travelling alone or heterosexual couples travelling together. As noted above, recommended waiting periods vary.

- During travel and for at least 8 weeks after the last day in a Zika-affected country, or from the time of diagnosis of infection, for females travelling alone or femalefemale couples travelling together.

Recommendations regarding Zika virus prevention (such as recommended waiting periods) may change as additional research on Zika virus infectivity emerges. Clinicians are advised to stay up to date with the latest recommendations released by the CDC (https://www.cdc.gov/zika/index.html), WHO (http://www.who.int/ emergencies/diseases/zika/en/) and Australia's Department of Health (http://www. health.gov.au/internet/main/publishing.nsf/content/ohp-zika.htm).

\section{Key Reading}

Australasian Society for HIV, Viral Hepatitis and Sexual Health Medicine (ASHM). Post-exposure prophylaxis after non-occupational and occupational exposure to HIV, Australian National Guidelines (Second edition). http://www.pep.guidelines.org.au. Accessed 1 Aug 2018.

Eddleston M, Davidson R, Brent A, Wilkinson R. Oxford handbook of tropical medicine. 3rd ed. Oxford: Oxford University Press; 2009. 
Farrar J, Hotez P, Junghanss T, Kang G, Lalloo D, White N. Manson's tropical diseases. 23rd ed. London: Saunders; 2013.

Guerrant RL, Walker DH, Weller PF. Tropical infectious diseases: principles, pathogens and practice. 3rd ed. Philadelphia: Churchill Livingstone; 2011.

Jensenius M, Parola P, Raoult D. Threats to international travellers posed by tick-borne diseases. Travel Med Infect Dis. 2006;4(1):4-13.

McGuinness SL, Wu H. Pre-travel considerations for non-vaccine-preventable travel infections. In: Keystone J, Kozarsky P, Connor B, Nothdurft H, Mendelson M, Leder K, editors. Keystone travel medicine. 4th ed. New York: Elsevier; 2018.

O'Brien D, Leder K, Matchett E, Brown GV, Torresi J. Illness in returned travelers and immigrants/refugees: the 6-year experience of two Australian infectious diseases units. J Travel Med. 2006;13:145-52.

O'Brien D, Tobin S, Brown GV, Torresi J. Fever in returned travellers: review of hospital admissions for a 3-year period. Clin Infect Dis. 2001;33(5):603-9.

Polen KD, Gilboa SM, Hills S, et al. Update: interim guidance for preconception counseling and prevention of sexual transmission of Zika virus for men with possible Zika virus exposureUnited States, August 2018. MMWR. 2018;67(31):868-71.

Steffen R. Travel medicine-prevention based on epidemiological data. Trans R Soc Trop Med Hyg. 1991;85(2):156-62.

Wilson ME, Weld LH, Boggild A, Keystone JS, et al. Fever in returned travelers: results from the GeoSentinel Surveillance Network. Clin Infect Dis. 2007;44:1560-8.

World Health Organization. Zika virus classification tables [Internet]. 2018. http://www.who.int/ emergencies/zika-virus/classification-tables/en/. Accessed 08. 